IZA DP No. 9893

Developments in Undernutrition in Indian

Children Under Five: A Decompositional Analysis

Peng Nie

Anu Rammohan

Wencke Gwozdz

Alfonso Sousa-Poza

April 2016 


\title{
Developments in Undernutrition in Indian Children Under Five: A Decompositional Analysis
}

\author{
Peng Nie \\ University of Hohenheim
}

Anu Rammohan

University of Western Australia

Wencke Gwozdz

Copenhagen Business School

\author{
Alfonso Sousa-Poza \\ University of Hohenheim and IZA
}

Discussion Paper No. 9893

April 2016

\author{
IZA \\ P.O. Box 7240 \\ 53072 Bonn \\ Germany \\ Phone: +49-228-3894-0 \\ Fax: +49-228-3894-180 \\ E-mail: iza@iza.org
}

\begin{abstract}
Any opinions expressed here are those of the author(s) and not those of IZA. Research published in this series may include views on policy, but the institute itself takes no institutional policy positions. The IZA research network is committed to the IZA Guiding Principles of Research Integrity.

The Institute for the Study of Labor (IZA) in Bonn is a local and virtual international research center and a place of communication between science, politics and business. IZA is an independent nonprofit organization supported by Deutsche Post Foundation. The center is associated with the University of Bonn and offers a stimulating research environment through its international network, workshops and conferences, data service, project support, research visits and doctoral program. IZA engages in (i) original and internationally competitive research in all fields of labor economics, (ii) development of policy concepts, and (iii) dissemination of research results and concepts to the interested public.
\end{abstract}

IZA Discussion Papers often represent preliminary work and are circulated to encourage discussion. Citation of such a paper should account for its provisional character. A revised version may be available directly from the author. 
IZA Discussion Paper No. 9893

April 2016

\section{ABSTRACT}

\section{Developments in Undernutrition in Indian Children Under Five: A Decompositional Analysis}

This study uses two waves (2004-2005 and 2011-2012) of the nationally representative Indian Human Development Survey to conduct a systematic decompositional analysis of the demographic and socio-economic factors contributing to undernutrition among children under five in India. The analytic method combines three types of decomposition: Blinder- Oaxaca, non-linear, and unconditional quantile. Child undernutrition is measured by $z$-scores for height-for-age ( $H A Z)$, weight-for-height (WHZ), weight-for-age (WAZ), and for the Composite Index of Anthropometric Failure (CIAF). Although our results show modest improvements on some measures, undernutrition among India's young children remains widespread. The improvements we do identify are partly attributable to changes in household wealth and maternal characteristics like body mass index and education.

JEL Classification: I15, I31, C21

Keywords: child undernutrition, India, decomposition

Corresponding author:

Alfonso Sousa-Poza

University of Hohenheim

Institute for Health Care \& Public Management

Fruwirthstr. 48

70599 Stuttgart

Germany

E-mail: alfonso.sousa-poza@uni-hohenheim.de 


\section{Developments in Undernutrition in Indian Children Under Five: A Decompositional Analysis}

\section{Introduction}

The United Nations (UN) regards improved child health as a key indicator of progress towards number three of its Sustainable Development Goals: a universal guarantee of a healthy life and well-being at all ages. Since an estimated one-third of deaths among children under five are attributable to undernutrition, child nutritional levels are an important means of gauging the condition of a country's children. Undernutrition not only puts children at a greater risk of disease vulnerability, it also adversely affects their physical, cognitive, and mental development (Barker, 1995). It can thus be expected to adversely impact productivity in later life (Strauss \& Thomas, 1995). In fact, eliminating childhood undernutrition should cut child mortality by over $50 \%$ and reduce the burden of diseases by about $20 \%$ (Murray \& Lopez, 1997; Pelletier, 1994; Tomkins \&Watson, 1989).

Globally, India performs poorly across most standard child nutritional measures, and accounts for more than $40 \%$ of global stunting (Haddad et al., 2015). Moreover, data from the India's nationally representative National Family Health Survey (NFHS), conducted in 1992, 1998-99, and 2005-06, paint a bleak picture of child nutrition in the country. In 2005-06, an estimated $38.4 \%$ of children under three were stunted and $46 \%$ were underweight. Although both these indicators have improved slightly since 1998-99, wasting, defined as an abnormally low weight for the child's height, still affects $19 \%$ of children under three with a slight deterioration from 1998-99 (UNDP, 2007). In fact, a recent NFHS-based analysis of trends in infant undernutrition in India between 1992 and 2005 reveals a 49\%, 44\%, and 40\% overall prevalence of underweight in 1992, 1998, and 2005, respectively (Subramanyam, Kawachi, Berkman, \& Subramanian, 2010) with a corresponding 52\%, 51\%, and 45\% prevalence of stunting. Hence, although child nutrition indicators suggest small improvements, unacceptably large numbers of Indian children are still nutritionally compromised. 
The aim of this paper, therefore, is to use the 2004-05 and 2011-12 data from the Indian Human Development Survey (IHDS) to conduct a comprehensive decompositional analysis of the demographic and socio-economic factors contributing to changes in childhood undernutrition outcomes in India. Our undernutrition measure is z-scores for weight-forheight (WHZ), height-for-age (HAZ), weight-for-age (WAZ), and the Composite Index of Anthropometric Failure (CIAF). In particular, we seek to identify the demographic and socioeconomic factors that influence changes in the nutritional status of children aged 0-5 years during the 2004-2012 period. We employ both linear Blinder-Oaxaca (BO) and non-linear decomposition (Fairlie, 1999), as well as the unconditional quantile technique developed by Firpo, Fortin, and Lemieux (2009) to evaluate the impact of distributional changes in observed characteristics on the unconditional marginal distribution of the three undernutrition measures (z-scores). Our analysis provides the most up-to-date profile of the nutritional status of India's children.

In general, we show that stunting, underweight, and anthropometric failure improved slightly over the 2004/2005-2011/2012 period but wasting became slightly worse. Nevertheless, severe wasting, stunting, and underweight all improved a little. In all three decompositional analyses (Blinder-Oaxaca, non-linear, unconditional quantile), these small changes in undernutrition measures are partly explainable by household economic conditions (household wealth), although maternal characteristics like mother's body mass index (BMI) and education also make a noticeable contribution.

The remainder of the study is structured as follows: Section 2 reviews the relevant literature on child undernutrition in India, section 3 describes the data and methods, and section 4 reports the results. Section 5 concludes the paper.

\section{Prior studies}

2.1 Socio-economic factors of child undernutrition in India

A large body of research using nationally representative secondary data sets to investigate the socio-economic factors associated with poor child nutrition in India suggests that inequalities appear to be increasing for vulnerable groups such as girls and individuals in lower socioeconomic groups (Brennan, McDonald, \& Shlomowitz, 2004; Gragnolati, Shekar, Das Gupta, Bredenkamp, \& Lee, 2005; Lokshin, Das Gupta, Gragnolati, \& Ivaschenko, 2005; Tarozzi \& 
Mahajan, 2007). However, whereas Tarozzi and Mahajan (2007) find an increase in gender inequities in child nutrition over the 1990s, with the nutrition of boys in India improving substantially more than that of girls; Pathak and Singh (2011) show that over the 1992-2006 period, the burden of undernutrition was disproportionately concentrated among poor children. Pathak and Singh (2011) further demonstrate that child differences in nutritional outcomes have widened between rich and poor households, and that child nutritional outcomes are relatively better in areas where households have been able to access Integrated Child Development Services (ICDS). One objective of this Government of India funded program is to improve the nutritional and health status of children in the $0-6$ age group, while also reducing mortality, sickness, undernutrition, and school dropout rates. Pathak and Singh's findings are consistent with Subramanyam et al.'s (2010) conclusion that over these 14 observation years, social disparities in undernutrition either widened or stayed the same.

Other recent studies focus either on undernutrition among Indian children or on India's declining nutritional intake (Gragnolati et al., 2005; Lokshin et al., 2005; Pathak \& Singh, 2011; Tarozzi \& Mahajan, 2007), which reflects a strong reduction in per capita calorie consumption despite robust economic growth over the 1990s (Deaton \& Dréze, 2009; Ray, 2007; Ray \& Lancaster, 2005). The trends observed in these studies suggest a possible nexus between the poor nutritional outcomes of young children and household calorie consumption. Another strand of literature, however, concentrates on the role of poor health infrastructure. For example, Paul et al. (2011) attribute the poor nutritional outcomes among Indian children to weak health systems and a policy focus on children aged 3-6 years at the expense of those aged 0-2 years, even though much of the growth occurs over this latter age.

More recent studies by Spears (2012) and Hammer and Spears (2013) explain poor child nutrition among Indian children in terms of sanitation, arguing that environmental threats from open defecation and exposure to faecal germs reduce nutrient absorption, while exposure to early life disease leads to undernutrition, stunting, and diarrhoea. Using data from the NFHS, Spears (2013) shows that open defecation remains exceptionally widespread in India and sanitation has not improved substantially despite rapid economic growth. However, although these studies provide useful benchmarks for assessing child nutritional outcomes and the socio-economic factors that influence them, they are based on National Family and Health Survey (NFHS) and National Sample Survey (NSS) data sets that are over a decade old. 
2.2 Applying decomposition: explaining the socio-economic factors underlying child undernutrition in India

Several empirical studies employ various decompositional approaches to analyse the gap in child undernutrition/health between certain groups (such as poor/non-poor, Muslims/Hindu, rural/urban). For example, Kumar and Singh (2013) apply BO decomposition to 2005-2006 NFHS data to measure the gap in under-five child undernutrition between poor and non-poor households in urban India. They identify the main contributing factors as underutilization of health care services, poor body mass index (BMI) in mothers, and low levels of parental education among impoverished urbanists. In earlier work, Bhalotra, Valente, and van Soest (2010) apply non-linear decomposition (Fairlie, 2006) to three waves of the NFHS $(1992 / 1993,1998 / 1999$, and 2005/2006) to measure the Hindu-Muslim gap in under-five child undernutrition as measured by stunting and wasting. They show that the $29 \%$ difference in stunting is mainly attributable to maternal education, maternal age at parturition, and child's birth year, while the $20 \%$ gap in wasting is primarily explainable by maternal education and state of residence. In a regression-based decomposition of the same data sets to assess (concentration index-based) inequalities in under-five child mortality and undernutrition outcomes, Chalasani (2012) identifies wealth and mother's education as the two largest contributors to severe stunting and severe underweight inequality over the 1992/1993 - 2005/2006 period. These results are supported by Kumar and Kumari (2014), who use BO decomposition to show that household economic status (wealth score) and parental education are the most significant contributors to the rural-urban gap in childhood undernutrition in India (measured as z-scores of weight-for-age). Similarly, Mazumdar (2010) identifies household wealth and mother's education as the two largest contributors to inequality in child undernutrition, and emphasizes the importance of poverty in explaining the child undernutrition inequalities revealed by the 2005/2006 NFHS. On the other hand, Van de Poel and Speybroeck (2009), in their earlier BO decomposition of 1998/1999 IDHS data, attribute the observed child undernutrition gap between scheduled castes and scheduled tribes primarily to lower wealth, education level, and use of health care services. In a more recent analysis of 2005/2006 NFHS data, Cavatorta, Shankar, and Flores-Martinez (2015) apply Machado and Mata's (2005) conditional quantile decomposition approach (among 
other methods) to show that the surprisingly modest height-for-age disparities across six Indian states ${ }^{1}$ can be explained by covariate differences in endowment effects.

In sum, past analyses of undernutrition changes in Indian children under five point to household economic status (particularly wealth) and maternal education as the two most important contributors. With few exceptions, however, this research uses BO decomposition, which can provide misleading estimates when the outcome variable is binary and explanatory variables differ substantially across groups (Fairlie, 2016). To our knowledge, only two studies analyse child undernutrition using non-linear decomposition: Bhalotra et al. (2010), who use the Fairlie (1999) method to identify Hindu-Muslim disparities in under-five child mortality and undernutrition, and Cavatorta et al. (2015), who employ Machado and Mata's (2005) conditional quantile decomposition technique to explore the relative contributions of covariates and coefficients over the entire height-for-age distribution. However, we can find no previous studies using the Fairlie (1999) non-linear decomposition to examine anthropometric failure differences between groups or over time, and the Machado and Mata (2005) method is not extendable to a detailed decomposition for each determinant (Edoka, 2012). We remedy both these problems in our present analysis of newly released IHDS data for 2004-05 and 2011-12. First, by taking into account binary measures of childhood undernutrition (wasting, stunting, underweight, and anthropometric failure), we are able to apply Fairlie's (1999) non-linear decompositional approach to new variables (in particular, CIAF). Likewise, by using re-centred influence function regression (RIFR) in our unconditional quantile regression decomposition of the disaggregated contributions of individual determinants at different quantiles, we remedy the limitations of the conditional quantile regression used by Machado and Mata (2005).

\section{Data and methods}

\subsection{Data}

The data for this analysis are taken from the India Human Development Survey (IHDS), a collaborative research program between researchers from the National Council of Applied Economic Research, New Delhi, and the University of Maryland. Designed primarily to document changes in Indian households' daily lives during an era of rapid transformation,

\footnotetext{
1 The selected states are Tamil Nadu, Bihar, Uttar Pradesh, Madhya Pradesh, Odisha and Gujarat.
} 
this nationally representative multi-topic survey was administered to households in 1,503 villages and 971 urban neighbourhoods across India. The first phase, IHDS-I (2004-2005), comprised two one-hour interviews with each household on such topics as health status, education, employment, economic status, marriage, fertility, gender relations, and social capital. The second phase, IHDS-II (2011-2012), consisted mostly of re-interviews with the same households.

Our analytic sample is restricted to children under five for whom detailed information is available on household socio-economic, demographic, and labour market characteristics. Because data on certain outcome variables of interest are limited, our final pooled sample contains 8,481 observations for wasting, 8,418 observations for stunting, 9,962 observations for underweight, and 7,424 observations for the CIAF.

\subsection{Study variables}

\subsubsection{Dependent variables}

In line with the World Health Organization's new reference standards (WHO Multicentre Growth Reference Study Group, 2006), we first measure the children's nutritional outcomes conventionally using z-scores of height-for-age ( $H A Z$ ), weight-for-height (WHZ), and weightfor-age (WAZ). As demonstrated in a seminal article by Waterlow et al. (1977), the heightfor-age and the weight-for-height $z$-scores, each expressed in standard deviations from the reference population mean, ${ }^{2}$ are good indicators of nutritional status. Whereas HAZ measures long-term nutrition by showing the cumulative effects of growth deficiency (often associated with chronic insufficient food intake, frequent infections, sustained incorrect feeding practices, and/or low socio-economic family status), WHZ reflects child growth and is typically seen as a measure of short- rather than long-term health status (Maitra, Rammohan, Ray, \& Robitaille, 2013). The WAZ z-score, on the other hand, is able to reflect both acute and chronic undernutrition, making it a better single indicator of childhood undernutrition (Deaton \& Dréze, 2009).

Based on these $z$-scores, we calculate three measures of undernutrition: wasting, stunting, and underweight. Children with values below -2 (below -3) of the reference population are considered undernourished (severely undernourished) (WHO Multicentre Growth Reference

\footnotetext{
${ }^{2}$ The reference population includes approximately 8,500 children from widely different ethnic backgrounds and cultural settings (Brazil, Ghana, India, Norway, Oman, and the U.S.).
} 
Study Group, 2006). It should be noted, however, that to facilitate interpretation in the BO decomposition model, we decompose only the negative z-scores of WHZ, WAZ, and HAZ (cf. Kumar \& Singh, 2013; Uthman, 2009; Van de Poel \& Speybroeck, 2009). Because these three conventional undernutrition measures reflect different aspects of anthropometric failure, however, they cannot individually determine the overall prevalence of child undernutrition in a population (Nandy, Irving, Gordon, Subramanian, \& Smith, 2005; Nandy \& Svedberg, 2012; Svedberg, 2000). They thus tend to underestimate the true extent of undernutrition, primarily due to the overlapping of children into multiple categories of anthropometric failure (Nandy et al., 2005; Nandy \& Svedberg, 2012; Sen \& Mondal, 2012). For instance, underweight cannot identify children who are suffering from underweight combined with stunting and/or wasting (Nandy \& Svedberg, 2012; Sen \& Mondal, 2012).

We remedy this weakness by using the composite index of anthropometric failure (CIAF), first proposed by Svedberg (2000) as an aggregated single anthropometric proxy for the overall estimation of malnourished children. In our analysis, we combine Nandy et al.'s (2005) Group Y, underweight only, with six of Svedberg's groups (2000): Group A, no failure; Group B, wasting only; Group C, wasting and underweight; Group D, wasting, stunting, and underweight; Group E, stunting and underweight; and Group F, stunting only (see Table A1 for a detailed classification). CIAF is thus a dummy variable for which 0 indicates no failure and 1 signals one or more anthropometric failures.

\subsubsection{Explanatory variables}

Our explanatory variables encompass four types of characteristics: maternal, economic, hygienic, and other.

Maternal characteristics. This category includes two variables shown to be critical to child nutritional outcomes: mother's educational attainment and maternal BMI. The first is measured on a 4-point scale from 1 = no education, 2 = primary school, 3 = secondary school, to 4 = tertiary and above; the second is reported weight $(\mathrm{kg})$ divided by height squared (m). The link between maternal body weight and child nutrition is well established in the literature: a child's growth and development is likely to be influenced by maternal nutrition history as reflected by BMI. Typically, a BMI under 18 is considered underweight and possibly malnourished, $20-25$ is considered healthy, 26-30 is overweight, and over 30 is obese. 
Economic characteristics. We measure a household's economic status using the household wealth index included in the data set, which is divided into five population quintiles from the poorest to the wealthiest 20 percent of households (see Filmer \& Pritchett, 2001). This index is calculated based on 33 dichotomous items measuring household ownership of assets and housing quality. These wealth quintiles are summed using principal component analysis, which provides a reasonably reliable measure of household economic status, one less likely to be affected by the transitory nature of labour income. Relative to income and consumption, therefore, the household assets measure is the least volatile and thus arguably a better longrun measure for household economic status.

Hygienic characteristics. The adverse effects on child growth of poor hygiene are confirmed by Prüss-Üstün, Bos, Gore, and Bartram (2008), who show that an estimated half of all cases of undernutrition in children under five are caused by unsafe water, inadequate sanitation, or insufficient hygiene. We therefore include among our explanatory variables three dummies that capture the level of sanitation and hygiene practised in the household: drinking water source, flushing toilet, and hand-washing behaviour. The drinking water source dummy equals 1 if the household's drinking water is piped or supplied by tube well or hand pump; 0 otherwise. The flushing toilet dummy equals 1 if the household has access to a flushing toilet; 0 otherwise. The hand-washing dummy equals 1 if the mother washes her hands after defecating; 0 otherwise.

Other (control) characteristics. Our specifications also include two child characteristics: age and gender. The child age dummy is divided into three categories $(0 \leq$ age $\leq 1$ year, $1<$ age $\leq$ 3 years, and 3 years $\leq$ age $<5$ years) so as to capture any possible non-linearities, which could be important given the long-run implications of undernutrition at an early age (see GranthamMcGregor, 1995; Maitra et al., 2013). The gender dummy equals 1 if the child is male; 0 otherwise. We also control for the father's education measured in the same way as the mother's. Because religion and caste both appear related to child undernutrition (see, e.g., Bhalotra et al., 2010), we also include dummies for these, each again divided into three categories: 1 = Hindu, $2=$ Muslim, $3=$ other; and $1=$ other castes, $2=$ other backward castes, $3=$ scheduled castes or tribes. To control for possible regional differences, we include a rural dummy ( $1=$ rural, $0=$ urban) and also a set of state dummies (cf. Maitra et al., 2013) to capture any state-level policies that influence child undernutrition. 


\subsection{Estimation procedure}

\subsubsection{Blinder-Oaxaca (BO) decomposition}

We use BO decomposition to explain differences in the nutritional measures $W H Z, H A Z$, and $W A Z$ as a function of selected explanatory factors. For a linear regression, the mean-based BO decomposition of child undernutrition over time is based on the assumption that the relation between child undernutrition and a set of socio-economic and demographic characteristics is linear and additive. One advantage of BO decomposition over regression analyses is that it quantifies the contribution of specific factors accounting for the average gap in an outcome (Blinder, 1973; Oaxaca, 1973). More specifically, it not only quantifies the distribution differences of factors that explain the average gap, it identifies the differences in these factors' effects (Jann, 2008; Kumar \& Singh, 2013). In our case, the total difference in mean z-scores of our three measures of child undernutrition can be decomposed as follows:

$$
\bar{Y}^{2011 / 12}-\bar{Y}^{2004 / 05}=\left(\bar{X}^{2011 / 12}-\bar{X}^{2004 / 05}\right) \hat{\beta}^{2011 / 12}+\bar{X}^{2004 / 05}\left(\hat{\beta}^{2011 / 12}-\hat{\beta}^{2004 / 05}\right)
$$

where $\bar{X}^{i}$ is a vector of the averaged values of the independent variables and $\hat{\beta}^{i}$ is a vector of the coefficient estimates for wave $i$ (here, $i=2004 / 2005,2011 / 2012$ ).

\subsubsection{Re-centred influence function regression (RIFR) decomposition}

Because covariate versus coefficient contributions may differ between the median and upper tail of the childhood undernutrition distribution and its lower tail (where severe undernutrition is more likely to be prevalent), we use RIFR decomposition (Firpo et al., 2009) to investigate the contributions of demographic and socio-economic characteristics at different quantiles of the unconditional marginal distribution. As highlighted by Srinivasan, Zanello, and Shankar (2013), such distribution-wide exploration could be valuable, especially when it targets the most vulnerable in a policy setting. The RIFR method involves a two-step procedure. In the first step, we calculate an influence function (IF) at each quantile $\tau$ of the distribution of the outcome variable ( $z$-score of child undernutrition), which is obtained as follows:

$$
\operatorname{RIF}\left(\text { zscore } ; q_{\tau}\right)=q_{\tau}+\left(\tau-1\left[\text { zscore } \leq q_{\tau}\right]\right) / f_{\text {zscore }}\left(q_{\tau}\right)
$$

where $q_{\tau}$ represents the unconditional $\tau t h$ quantile of the z-score, $f_{\text {zscore }}\left(q_{\tau}\right)$ is the unconditional density of the $z$-score at the $\tau$ th quantile, and $1\left[\right.$ zscore $\left.\leq q_{\tau}\right]$ is an indicator 
function for whether the outcome variable is small or equal to the $\tau$ th quantile. For each quantile, the coefficient on $X$ for waves 2004/2005 and 2011/2012 are then estimated by regressing the RIF on $X$ :

$$
q_{\text {wave }, \tau}=E_{X}\left[E\left[\widehat{R I F}\left(\text { zscore } ; q_{\text {wave }, \tau}\right) \mid X_{\text {wave }}\right]\right]=E\left[X_{\text {wave }}\right] \widehat{\theta}_{\text {wave }, \tau}
$$

where $q_{\text {wave, } \tau}$ is the unconditional $\tau t h$ quantile of the $z$-score for wave $2004 / 05$ and $2011 / 12$, respectively. $\hat{\theta}_{\text {wave, } \tau}$ is the coefficient of the unconditional quantile regression, which captures the marginal effect of a change in the distribution of $X$ on the unconditional quantile of the $z$-score.

In the second step, we employ the BO decomposition strategy at different quantiles $(25 \%$, $50 \%$, and $75 \%$ ) calculated by the RIFR:

$$
\begin{gathered}
\widehat{\Delta}_{z s c o r e}^{\tau}=\left[\widehat{\operatorname{RIF}}\left(\text { zscore }_{2011 / 12} ; q_{2011 / 12, \tau}\right)\right]-\left[\widehat{\operatorname{RIF}}\left(\text { zscore }_{2004 / 05} ; q_{2004 / 05, \tau}\right)\right] \\
\widehat{\Delta}_{z s c o r e}^{\tau}=\left(\bar{X}_{2011 / 12}-\bar{X}_{2004 / 05}\right) \hat{\theta}_{2011 / 12, \tau}+\bar{X}_{2004 / 05}\left(\widehat{\theta}_{2011 / 12, \tau}-\widehat{\theta}_{2004 / 05, \tau}\right.
\end{gathered}
$$

Both the explained and unexplained parts are then decomposed into the contributions of each covariate at the $\tau t h$ quantile in equation (5), which is in effect analogous to the BO decomposition in equation (1).

\subsubsection{Fairlie’s (1999) non-linear decomposition}

As stressed by Fairlie (2016), applying standard BO decomposition to a linear probability model provides misleading estimates when dependent variables are binary, particularly if the group differences for an influential independent variable are relatively large. In this case, it is preferable to apply a relatively straightforward simulation technique for non-linear decomposition. Accordingly, in estimating the contributions of socio-economic and demographic factors to identified differences in our key undernutrition indicators - (severe) wasting, stunting, underweight, and the combined CIAF indicator - we follow Fairlie (1999) by employing a non-linear decomposition approach when the dependent variable is binary. Here, wasting, stunting, underweight, and overall anthropometric failure are the dependent variables, so the decomposition for the non-linear equation, $Y=F(\mathrm{X} \hat{\beta})$, can be expressed as 
$\bar{Y}^{2011 / 12}-\bar{Y}^{2004 / 05}$

$$
\begin{aligned}
& =\left(\sum_{i=1}^{N^{2011 / 12}} \frac{F\left(X_{i}^{2011 / 12} \hat{\beta}^{2004 / 05}\right)}{N^{2011 / 12}}-\sum_{i=1}^{N^{2004 / 05}} \frac{F\left(X_{i}^{2004 / 05} \hat{\beta}^{2004 / 05}\right)}{N^{2004 / 05}}\right) \\
& +\left(\sum_{i=1}^{N^{2011 / 12}} \frac{F\left(X_{i}^{2011 / 12} \hat{\beta}^{2011 / 12}\right)}{N^{2011 / 12}}-\sum_{i=1}^{N^{2011 / 12}} \frac{F\left(X_{i}^{2011 / 12} \hat{\beta}^{2004 / 05}\right)}{N^{2011 / 12}}\right)
\end{aligned}
$$

where $N^{j}$ denotes the sample size of each wave $(j=2004 / 2005,2011 / 2012)$. Two aspects are worth noting: First, the BO decomposition in equation (1) is a special case of equation (6) where $F\left(X_{i} \beta\right)=X_{i} \beta$. Second, in equations (1) and (6), the first (explained) term on the right indicates the contribution resulting from a difference in the distribution of the determinant of $X$, and the second (unexplained) term refers to the part attributable to a difference in the effect of the determinants. Equally noteworthy, the second term captures all the potential effects of differences in unobservables (Fairlie, 2016). Here, in keeping with the majority of previous research using decomposition, we focus on the explained terms and their disaggregated contribution for individual covariates, which result primarily from the difficulty of interpreting the unexplained part. ${ }^{3}$ The contribution of a variable is given by the average change in function if that variable is changed while all other variables remain the same. It should further be noted that for severe childhood undernutrition in terms of $W H Z$, $H A Z$, and WAZ, we use the same specification as in equation (6).

One potential concern related to Fairlie's (1999) sequential decomposition is path dependence, the possibility that changing the order of variables in the decomposition may produce different results (Fairlie, 2016; Schwiebert, 2015). We therefore test the decomposition estimates' sensitivity to variable re-ordering by randomizing their order in the decomposition (Fairlie, 2016; Schwiebert, 2015). As Fairlie (2016) also emphasizes, however, the decomposition procedure approximates the average decomposition over all possible orderings while preserving the summing up of properties by using a large number of replications. We therefore use 1,000 replications, the minimum number recommended for most applications (see, e.g., Fairlie, 2016). As a robustness check, we also perform an analysis using 5,000 replications.

When reporting the two-fold (explained vs. unexplained) decomposition results for these three decompositional methods, we categorize the disaggregated contributions of the

\footnotetext{
${ }^{3}$ For a more detailed discussion of the unexplained part, see Jones (1983).
} 
determinants in the explained part into four main dimensions: maternal characteristics (mother's BMI and its squared term; mother's primary, secondary, tertiary school and above), household economic status (household wealth: poorest, poor, middle, rich, and richest); hygiene (the sum of water source, flushing toilet, and hand washing); and other (child age dummy for $1<$ age $\leq 3$ and $3 \leq$ age $<5$; child gender dummy; father's primary, secondary, tertiary school and above; caste: other backwards, schedules castes and tribes; religion: Muslim and other; and finally, 32 state dummies and a rural dummy).

\section{Results}

\subsection{Descriptive statistics}

As Table 1 shows, stunting, underweight, and anthropometric failure improved modestly over the $2004 / 2005$ to $2011 / 2012$ period (a $44.0 \%$ to $35.5 \%$ decline in stunting, $33.1 \%$ to $27.2 \%$ in underweight, and $58.4 \%$ to $49.4 \%$ in CIAF). Wasting, however, slightly worsened over the same period, increasing from $16 \%$ to $16.9 \%$. As regards severe undernutrition, all three individual indicators - wasting, stunting, and underweight - improved slightly during the same period; however, at different magnitudes: from $6.3 \%$ to $5.7 \%$ for severe wasting, from $25.4 \%$ to $17.5 \%$ for severe stunting, and $13.5 \%$ to $10.2 \%$ for severe underweight. Nonetheless, the CIAF indicates a much higher prevalence of undernutrition among children under five than do the individual measures, a finding well in line with previous observations (Nandy et al., 2005; Nandy \& Svedberg, 2012; Sen \& Mondal, 2012), and one that underscores the serious state of undernutrition among India's children.

Table 1 Descriptive statistics

\begin{tabular}{lccc}
\hline Variables & $2004-2005$ & $2011-2012$ & Mean difference \\
\hline Nutritional outcomes & & & $0.155^{* * *}$ \\
\hline Weight-for-height z-score (WHZ) & -0.473 & -0.628 & $-0.285^{* * *}$ \\
Height-for-age Z-score (HAZ) & -1.437 & -1.152 & $-0.147^{* * *}$ \\
Weight-for-age z-score (WAZ) & -1.092 & -0.945 & -0.010 \\
\hline Undernutrition measures & & & $0.085^{* * *}$ \\
\hline Wasting (WHZ<-2) & 0.160 & 0.169 & $0.059^{* * *}$ \\
Stunting $(H A Z<-2)$ & 0.440 & 0.355 & 0.005 \\
Underweight $(W A Z<-2)$ & 0.331 & 0.272 & $0.079^{* * *}$ \\
Severe wasting $(W H Z<-3)$ & 0.063 & 0.0570 & $0.033^{* * *}$ \\
Severe stunting $(H A Z<-3)$ & 0.254 & 0.175 & $0.090^{* * *}$ \\
Severe underweight $(W A Z<-3)$ & 0.135 & 0.102 & 0.494 \\
Anthropometric failure $(C I A F)$ & 0.584 & & \\
\hline
\end{tabular}




\begin{tabular}{|c|c|c|c|}
\hline \multicolumn{4}{|l|}{ Maternal characteristics } \\
\hline Mother's education: no education & 0.573 & 0.489 & $0.084^{* * *}$ \\
\hline Mother's education: primary & 0.087 & 0.101 & $-0.014^{* *}$ \\
\hline Mother's education: secondary & 0.293 & 0.368 & $-0.076^{* * *}$ \\
\hline Mother's education: tertiary and above & 0.048 & 0.042 & 0.006 \\
\hline Mother's BMI $\left(\mathrm{kg} / \mathrm{m}^{2}\right)$ & 20.510 & 20.74 & $-0.230^{* * *}$ \\
\hline \multicolumn{4}{|l|}{ Economic status } \\
\hline Household wealth: poorest & 0.344 & 0.199 & $0.145^{* * *}$ \\
\hline Household wealth: poor & 0.240 & 0.248 & -0.007 \\
\hline Household wealth: middle & 0.200 & 0.183 & $0.018^{* *}$ \\
\hline Household wealth: rich & 0.124 & 0.184 & $-0.060^{* * *}$ \\
\hline Household wealth: richest & 0.091 & 0.187 & $-0.095^{* * *}$ \\
\hline \multicolumn{4}{|l|}{ Hygiene } \\
\hline Water source & 0.837 & 0.848 & -0.011 \\
\hline Flushing toilet & 0.177 & 0.259 & $-0.082^{* * *}$ \\
\hline Hand washing & 0.992 & 0.993 & -0.001 \\
\hline \multicolumn{4}{|l|}{ Other controls } \\
\hline Child's age (in years): $0 \leq$ age $\leq 1$ & 0.307 & 0.309 & -0.002 \\
\hline Child's age (in years): $1<$ age $\leq 3$ & 0.213 & 0.205 & 0.008 \\
\hline Child's age (in years): $3<$ age $<5$ & 0.480 & 0.486 & -0.006 \\
\hline Child' gender $(1=$ male, $0=$ female $)$ & 0.513 & 0.524 & -0.011 \\
\hline Father's education: no education & 0.378 & 0.312 & $0.066^{* * *}$ \\
\hline Father’s education: primary & 0.101 & 0.127 & $-0.026^{* * *}$ \\
\hline Father's education: secondary & 0.445 & 0.487 & $-0.042^{* * *}$ \\
\hline Father's education: tertiary and above & 0.076 & 0.074 & 0.002 \\
\hline Caste: other & 0.242 & 0.208 & $0.034^{* * *}$ \\
\hline Caste: other backward & 0.408 & 0.399 & 0.009 \\
\hline Caste: scheduled caste/tribe & 0.350 & 0.393 & $-0.043^{* * *}$ \\
\hline Religion: Hindu & 0.766 & 0.763 & 0.003 \\
\hline Religion: Muslim & 0.168 & 0.196 & $-0.027^{* * *}$ \\
\hline Religion: other & 0.065 & 0.041 & $0.024^{* * *}$ \\
\hline Rural & 0.650 & 0.729 & $-0.080^{* * *}$ \\
\hline
\end{tabular}

Note: Mean values are reported for key variables in the IHDS 2004/2005 and 2011/2012. The significance of the mean difference is based on independent $t$-tests. $* p \leq .05, * * p \leq .01, * * * p \leq .001$.

Figure 1 reports the kernel densities of the $z$-scores stratified by year. Using a KolmogorovSmirnov test for the equality of distributions, we consistently reject the null hypothesis that the distributions are the same over the two survey waves. However, two points are worth emphasizing: First, the mass of the distribution for HAZ and WAZ in 2011/2012 lies to the right of the 2004/2005 wave, suggesting improvements in these two measures of child undernutrition. Second, a relatively small part of the WHZ distribution in 2011/2012 lies to the left of the 2004/2005 distribution, indicating a slight deterioration in the weight-to-height measure. This observation is consistent with Maitra et al.'s (2013) finding for the 1998/1999 - 2005/2006 period based on NFHS data. 

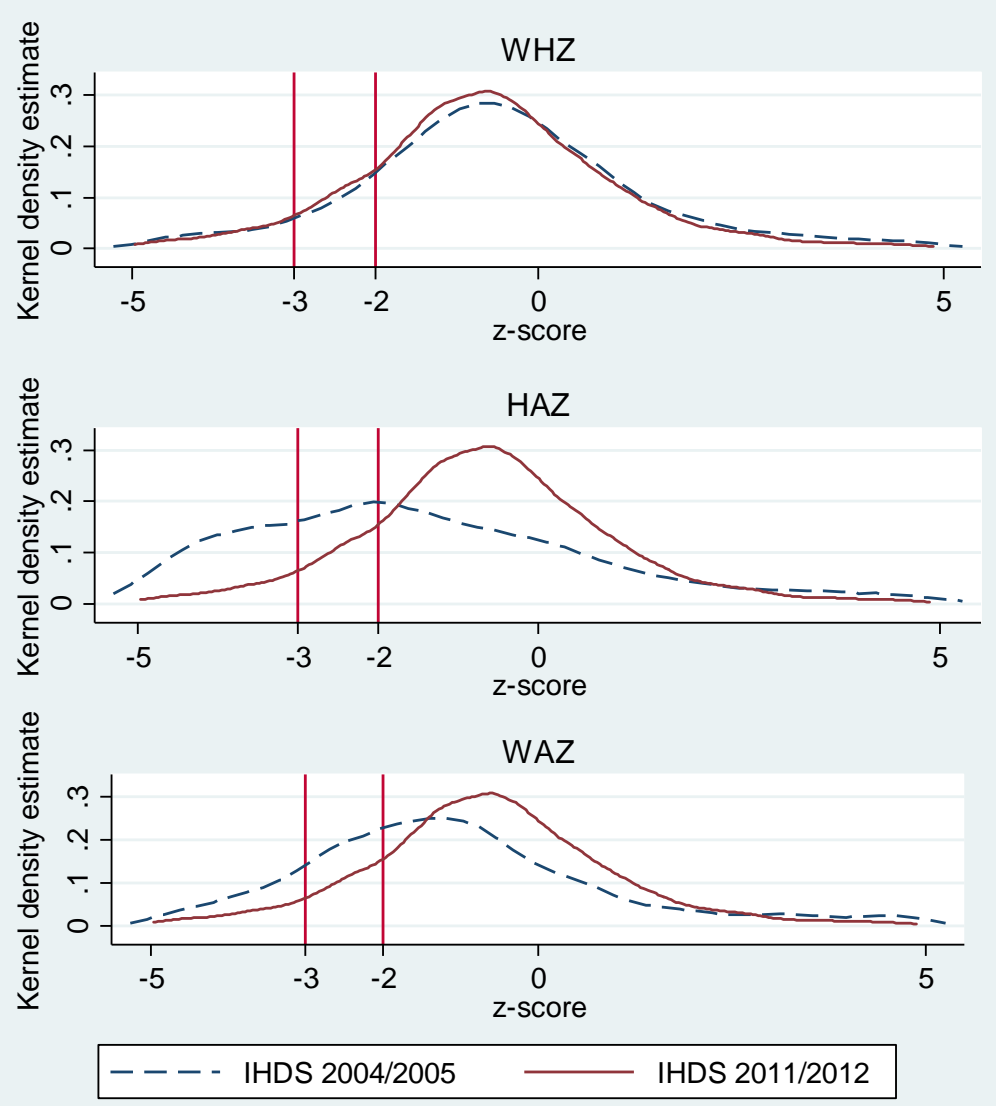

Figure 1 Kernel density estimates for WHZ, HAZ, and WAZ by year Note: Kolmogrov-Smirnov test $p$-value: $W H Z$ : combined K-S 0.048; $p$-value $=0.000 ;$ HAZ: combined K-S 0.098; $p$-value = $0.000 ;$ WAZ: combined K-S 0.062; $p$-value $=0.000$

4.2 Explaining the differences in nutritional outcomes

\subsubsection{Blinder-Oaxaca decomposition estimates}

The results of the conventional BO decomposition for the WHZ, HAZ, and WAZ Z-scores are reported in Table 2, with a (previously explained) focus on the explained part. This table reveals no significant explained differences in WHZ between 2004-2005 and 2011-2012. For HAZ and WAZ, however, which do document an improvement in undernutrition, the contributions of the explained part differ, with about $14-26 \%$ of the difference explainable by varying covariate endowments. As regards the separate contributions to the explained part made by differences in the individual distribution of each dimension, household economic status (measured by household wealth) is the most important contributor to explaining improvement in the average values of HAZ (115\%) and WAZ (84\%). The maternal characteristics such as mother's BMI and mother's education are also relatively important 
contributors (HAZ: 16\%; WAZ: 24\%). These results are well in line with the NFHS-based findings of Chalasani (2012), Van de Poel and Speybroeck (2009), and Mazumdar (2010), who also identify household wealth and maternal education as the two largest contributory factors to childhood undernutrition. The importance of household wealth in reducing poor nutrition outcomes is also in keeping with the descriptive statistics reported in Table 1, which indicate that between the 2004-2005 and 2011-2012 periods, the proportion of children under five declined in the poorest wealth quintile but increased in the two richest wealth quintiles.

Table 2 Blinder-Oaxaca (BO) decomposition of socio-economic differences in undernutrition among Indian children under five: IHDS 2004/2005-2011/2012

\begin{tabular}{|c|c|c|c|c|c|c|}
\hline & WHZ & Contribution & $H A Z$ & Contribution & WAZ & Contribution \\
\hline Overall & & $\%$ & & $\%$ & & $\%$ \\
\hline $2004-2005$ & $\begin{array}{c}-1.4179^{* * *} \\
(0.019)\end{array}$ & & $\begin{array}{c}-2.3455^{* * *} \\
(0.022)\end{array}$ & & $\begin{array}{c}-1.8944^{* * *} \\
(0.017)\end{array}$ & \\
\hline 2011-2012 & $\begin{array}{c}-1.3970^{* * *} \\
(0.020)\end{array}$ & & $\begin{array}{c}-2.0669^{* * *} \\
(0.024)\end{array}$ & & $\begin{array}{c}-1.7054^{* * *} \\
(0.019)\end{array}$ & \\
\hline Total difference & $\begin{array}{l}0.0209 \\
(0.028)\end{array}$ & & $\begin{array}{c}0.2786^{* * *} \\
(0.032)\end{array}$ & & $\begin{array}{c}0.1889^{* * *} \\
(0.026)\end{array}$ & \\
\hline Explained & & & $\begin{array}{c}0.0393^{* *} \\
(0.016)\end{array}$ & 14 & $\begin{array}{c}0.0494^{* * *} \\
(0.012)\end{array}$ & 26 \\
\hline Unexplained & & & $\begin{array}{c}0.2393^{* * *} \\
(0.034) \\
\end{array}$ & 86 & $\begin{array}{c}0.1395^{* * *} \\
(0.027) \\
\end{array}$ & 74 \\
\hline \multicolumn{7}{|l|}{ Explained part } \\
\hline Maternal characteristics & & & $\begin{array}{l}0.0073^{*} \\
(0.004)\end{array}$ & 19 & $\begin{array}{c}0.0118^{* * *} \\
(0.004)\end{array}$ & 24 \\
\hline Economic status & & & $\begin{array}{c}0.0453^{* * *} \\
(0.012)\end{array}$ & 115 & $\begin{array}{c}0.0415^{* * *} \\
(0.009)\end{array}$ & 84 \\
\hline Hygiene & & & $\begin{array}{l}0.0012 \\
(0.004)\end{array}$ & 3 & $\begin{array}{l}-0.0014 \\
(0.003)\end{array}$ & -3 \\
\hline Other & & & $\begin{array}{r}-0.0144 \\
(0.010) \\
\end{array}$ & -37 & $\begin{array}{r}-0.0024 \\
(0.007) \\
\end{array}$ & -5 \\
\hline$N$ & 5,669 & & 6,414 & & 7,686 & \\
\hline \multicolumn{7}{|c|}{$\begin{array}{l}\text { Note: The dependent variables are } z \text {-scores of weight-for-height, height-for-age, and weight-for-age. Maternal characteristics } \\
\text { are mothers' BMI and its squared term; and the mother's education categories of primary, secondary, and tertiary and above. } \\
\text { Household wealth is captured by the five wealth quintiles (with poorest as the reference category). Hygiene is access to } \\
\text { piped/tube water for drinking, a flushing toilet, and mother's hand-washing behaviour. Other variables in the group are child } \\
\text { age; gender; father's educational categories of primary, secondary, and tertiary and above; caste groups of other backward } \\
\text { and scheduled/tribes; religion groups of Muslim and others; state dummies for all states excluding Uttar Pradesh, and a rural } \\
\text { dummy. Standard errors are in parentheses. }{ }^{*} p<0.1,{ }^{* *} p<0.05,{ }^{* *} p<0.01 \text {. }\end{array}$} \\
\hline
\end{tabular}

\subsubsection{RIFR decomposition estimates}

In a next step, we investigate the explanatory power of demographic and socio-economic characteristics at different quantiles of the unconditional marginal distribution of the undernutrition distribution (see Table 3). Three major findings are worth highlighting: First, household wealth (a proxy for the household economic status) once again consistently makes the largest contribution to the overall explained part for both WAZ and HAZ (panels B and C, respectively). However, such is not the case for any of the three quantiles for the WHZ indicator (panel A), where the difference cannot be explained with the socio-economic 
variables used in the analysis. In fact, based on maternal characteristics, the $W H Z$ gap should be consistently smaller. In the case of $H A Z$ (panel B), in the lower parts of the distribution, about $10-11 \%$ of the gap can be explained with our variables, whereas in the upper part $75 \%$ quantile), the difference cannot be explained. In fact, in the $75 \%$ quantile, based on the considered determinants, the gap should be larger than it actually is. The fact that differences at the upper end of the distribution cannot be readily explained with the traditional determinants of undernutrition is not all that surprising. In the $25 \%$ quantile (i.e. those children particularly affected by undernutrition), the explained part of $10 \%$ can, to a large extent, be explained by household wealth. Turning to WAZ (panel C), we note that in the bottom part of the distribution, about $20-36 \%$ of the gap can be explained by our variables. Household wealth, once again, plays a main role, accounting for much of the explained part of the gap.

Table 3: RIFR decomposition of socio-economic differences in WHZ, HAZ, and WAZ among Indian children under five: IHDS 2004/2005-2011/2012

\begin{tabular}{|c|c|c|c|c|c|c|}
\hline \multirow[t]{2}{*}{ Panel A } & \multicolumn{6}{|c|}{ WHZ } \\
\hline & $25 \%$ & Contribution & $50 \%$ & Contribution & $75 \%$ & Contribution \\
\hline Overall & & $\%$ & & $\%$ & & $\%$ \\
\hline $2004-2005$ & $\begin{array}{c}-1.4884^{* * * *} \\
(0.027)\end{array}$ & & $\begin{array}{c}-0.5513^{* * *} \\
(0.026)\end{array}$ & & $\begin{array}{c}0.4443^{* * *} \\
(0.031)\end{array}$ & \\
\hline $2011-2012$ & $\begin{array}{c}-1.5492^{* * *} \\
(0.036)\end{array}$ & & $\begin{array}{c}-0.6641^{* * *} \\
(0.026)\end{array}$ & & $\begin{array}{c}0.2546^{* * *} \\
(0.036)\end{array}$ & \\
\hline Total difference & $\begin{array}{l}-0.0608 \\
(0.042)\end{array}$ & & $\begin{array}{c}-0.1128^{* * *} \\
(0.036)\end{array}$ & & $\begin{array}{c}-0.1897^{* * *} \\
(0.050)\end{array}$ & \\
\hline Explained & & & $\begin{array}{l}0.0242 \\
(0.017)\end{array}$ & -21 & $\begin{array}{l}0.0320 \\
(0.020)\end{array}$ & -17 \\
\hline Unexplained & & & $\begin{array}{c}-0.1370^{* * *} \\
(0.039) \\
\end{array}$ & 121 & $\begin{array}{c}-0.2217^{* * *} \\
(0.054)\end{array}$ & 117 \\
\hline \multicolumn{7}{|l|}{ Explained part } \\
\hline Maternal characteristics & & & $\begin{array}{c}0.0149^{* *} \\
(0.006)\end{array}$ & -62 & $\begin{array}{c}0.0204^{* * *} \\
(0.007)\end{array}$ & -64 \\
\hline Economic status & & & $\begin{array}{l}0.0063 \\
(0.012)\end{array}$ & -26 & $\begin{array}{l}0.0120 \\
(0.015)\end{array}$ & -38 \\
\hline Hygiene & & & $\begin{array}{l}0.0016 \\
(0.005)\end{array}$ & -7 & $\begin{array}{l}-0.0029 \\
(0.006)\end{array}$ & 9 \\
\hline Other & & & $\begin{array}{l}0.0015 \\
(0.012)\end{array}$ & -5 & $\begin{array}{l}0.0026 \\
(0.012)\end{array}$ & -7 \\
\hline$N$ & 8,481 & & 8,481 & & 8,481 & \\
\hline Panel B & \multicolumn{6}{|c|}{ HAZ } \\
\hline & $25 \%$ & Contribution & $50 \%$ & Contribution & $75 \%$ & Contribution \\
\hline Overall & & $\%$ & & $\%$ & & $\%$ \\
\hline $2004-2005$ & $\begin{array}{c}-2.9910^{* * *} \\
(0.041)\end{array}$ & & $\begin{array}{c}-1.7046^{* * *} \\
(0.034)\end{array}$ & & $\begin{array}{c}-0.1274^{* *} \\
(0.056)\end{array}$ & \\
\hline $2011-2012$ & $\begin{array}{c}-2.4898^{* * *} \\
(0.041)\end{array}$ & & $\begin{array}{c}-1.3866^{* * *} \\
(0.043)\end{array}$ & & $\begin{array}{l}0.0371 \\
(0.049)\end{array}$ & \\
\hline Total difference & $\begin{array}{c}0.5012^{* * *} \\
(0.056)\end{array}$ & & $\begin{array}{c}0.3180^{* * *} \\
(0.055)\end{array}$ & & $\begin{array}{l}0.1645^{* *} \\
(0.076)\end{array}$ & \\
\hline Explained & $\begin{array}{l}0.0506^{*} \\
(0.027)\end{array}$ & 10 & $\begin{array}{l}0.0359 \\
(0.030)\end{array}$ & 11 & $\begin{array}{r}-0.0667 \\
(0.040)\end{array}$ & -41 \\
\hline Unexplained & $\begin{array}{c}0.4506^{* * * *} \\
(0.062)\end{array}$ & 90 & $\begin{array}{c}0.2821^{* * *} \\
(0.056)\end{array}$ & 89 & $\begin{array}{c}0.2312^{* * *} \\
(0.073)\end{array}$ & 141 \\
\hline Explained part & & & & & & \\
\hline Maternal characteristics & $\begin{array}{l}0.0092 \\
(0.007)\end{array}$ & 18 & $\begin{array}{l}0.0101 \\
(0.008)\end{array}$ & 28 & $\begin{array}{l}-0.0015 \\
(0.010)\end{array}$ & 2 \\
\hline
\end{tabular}




\begin{tabular}{|c|c|c|c|c|c|c|}
\hline Economic status & $\begin{array}{c}0.0698^{* * *} \\
(0.019)\end{array}$ & 138 & $\begin{array}{c}0.0579^{* * *} \\
(0.017)\end{array}$ & 161 & $\begin{array}{l}0.0221 \\
(0.024)\end{array}$ & -33 \\
\hline Hygiene & $\begin{array}{l}0.0051 \\
(0.007)\end{array}$ & 10 & $\begin{array}{l}0.0037 \\
(0.007)\end{array}$ & 10 & $\begin{array}{r}-0.0012 \\
(0.010)\end{array}$ & 2 \\
\hline Other & $\begin{array}{r}-0.0335^{*} \\
(0.017)\end{array}$ & -66 & $\begin{array}{c}-0.0358^{*} \\
(0.020)\end{array}$ & -99 & $\begin{array}{c}-0.0861^{* * *} \\
(0.029)\end{array}$ & 129 \\
\hline$N$ & 8,418 & & 8,418 & & 8,418 & \\
\hline Panel C & \multicolumn{6}{|c|}{ WAZ } \\
\hline & $25 \%$ & Contribution & $50 \%$ & Contribution & $75 \%$ & Contribution \\
\hline Overall & & $\%$ & & $\%$ & & $\%$ \\
\hline $2004-2005$ & $\begin{array}{c}-2.3631^{* * *} \\
(0.029)\end{array}$ & & $\begin{array}{c}-1.3058^{* * *} \\
(0.033)\end{array}$ & & $\begin{array}{c}-0.1695^{* * *} \\
(0.039)\end{array}$ & \\
\hline 2011-2012 & $\begin{array}{c}-2.0723^{* * *} \\
(0.031)\end{array}$ & & $\begin{array}{c}-1.1190^{* * *} \\
(0.030)\end{array}$ & & $\begin{array}{c}-0.1120^{* * *} \\
(0.039)\end{array}$ & \\
\hline Total difference & $\begin{array}{c}0.2909^{* * *} \\
(0.040)\end{array}$ & & $\begin{array}{c}0.1869^{* * *} \\
(0.045)\end{array}$ & & $\begin{array}{l}0.0575 \\
(0.050)\end{array}$ & \\
\hline Explained & $\begin{array}{c}0.0581^{* * *} \\
(0.021)\end{array}$ & 20 & $\begin{array}{c}0.0666^{* * *} \\
(0.023)\end{array}$ & 36 & & \\
\hline Unexplained & $\begin{array}{c}0.2328^{* * *} \\
(0.046)\end{array}$ & 80 & $\begin{array}{c}0.1203^{* * *} \\
(0.043)\end{array}$ & 64 & & \\
\hline \multicolumn{7}{|l|}{ Explained part } \\
\hline Mother characteristics & $\begin{array}{c}0.0203^{* * *} \\
(0.006)\end{array}$ & 35 & $\begin{array}{c}0.0160^{* *} \\
(0.007)\end{array}$ & 24 & & \\
\hline Economic status & $\begin{array}{c}0.0470^{* * * *} \\
(0.014)\end{array}$ & 81 & $\begin{array}{c}0.0721^{* * *} \\
(0.013)\end{array}$ & 108 & & \\
\hline Hygiene & $\begin{array}{c}-0.0003 \\
(0.005)\end{array}$ & -1 & $\begin{array}{c}-0.0026 \\
(0.006)\end{array}$ & -4 & & \\
\hline Other & $\begin{array}{c}-0.0089 \\
(0.013)\end{array}$ & -15 & $\begin{array}{c}-0.0189 \\
(0.015)\end{array}$ & -28 & & \\
\hline$N$ & 9,962 & & 9,962 & & 9,962 & \\
\hline
\end{tabular}

4.3 Explaining the differences in undernutrition between 2004-2005 and 2011-2012

\subsubsection{Undernutrition in children under five at a $<-2$ standard deviation cut-off}

A useful way to measure the extent of the undernutrition is to classify the z-scores into the three levels suggested by Kassouf and Senauer (1996): (i) severe: z-score <-3, (ii) moderate: $z$-score in the -3 to -2 interval, and (iii) normal and mild (combined into one category): $z$ score larger than -2 . Given that all three undernutrition indicators (wasting, stunting, underweight) and the CIAF are binary measures, we estimate the non-linear decomposition regressions proposed by Fairlie (1999). Because our aim is to identify the factors that influence both general and severe undernutrition in children under five, in Tables 4 and 5, we report the results for cut-offs of -2 standard deviations (general undernutrition) and -3 standard deviations (severe undernutrition), respectively.

As Table 4 shows, the contributions of the explained part vary substantially for the different measures of child undernutrition: $6 \%$ for stunting, $22 \%$ for mild underweight, and $21 \%$ for the CIAF, with no significant explained differences for wasting. For the individual contribution of each dimension in the explained part, household economic status (household 
wealth) uniformly explains the largest proportion of improvements in stunting, underweight, and anthropometric failure, with contributions of $161 \%, 89 \%$, and $66 \%$, respectively. Likewise, maternal characteristics (including maternal BMI and education) explain 69\% of stunting, $48 \%$ of underweight, $23 \%$ of anthropometric failure. ${ }^{4}$

Table 4: Non-linear decomposition of socio-economic differences in undernutrition among Indian children under five: IHDS 2004/2005-2011/2012 (based on probit estimates)

\begin{tabular}{|c|c|c|c|c|c|c|c|c|}
\hline & Wasting & Contribution & Stunting & Contribution & Underweight & Contribution & CIAF & Contribution \\
\hline & & $\%$ & & $\%$ & & $\%$ & & $\%$ \\
\hline $2004-2005$ & 0.1595 & & 0.4398 & & 0.3314 & & 0.5842 & \\
\hline $2011-2012$ & 0.1691 & & 0.3546 & & 0.2724 & & 0.4943 & \\
\hline Total difference & 0.0096 & & -0.0852 & & -0.0590 & & -0.0899 & \\
\hline Explained & & & -0.0049 & 6 & -0.0132 & 22 & -0.0185 & 21 \\
\hline Unexplained & & & -0.0803 & 94 & -0.0458 & 78 & -0.0714 & 79 \\
\hline \multicolumn{9}{|l|}{ Explained part } \\
\hline Maternal characteristics & & & $\begin{array}{c}-0.0034^{* * *} \\
(0.001)\end{array}$ & 69 & $\begin{array}{c}-0.0063^{* * *} \\
(0.001)\end{array}$ & 48 & $\begin{array}{c}-0.0042^{* * *} \\
(0.001)\end{array}$ & 23 \\
\hline Economic status & & & $\begin{array}{c}-0.0079^{* *} \\
(0.004)\end{array}$ & 161 & $\begin{array}{c}-0.0117^{* * *} \\
(0.003)\end{array}$ & 89 & $\begin{array}{c}-0.0122^{* * *} \\
(0.004)\end{array}$ & 66 \\
\hline Hygiene & & & $\begin{array}{r}-0.0027 \\
(0.002)\end{array}$ & 55 & $\begin{array}{r}-0.0007 \\
(0.001)\end{array}$ & 5 & $\begin{array}{l}-0.0021 \\
(0.002)\end{array}$ & 11 \\
\hline Other & & & $\begin{array}{c}0.0092^{* * *} \\
(0.003)\end{array}$ & -187 & $\begin{array}{c}0.0054^{* * *} \\
(0.002)\end{array}$ & -42 & $\begin{array}{l}-0.0000 \\
(0.003)\end{array}$ & 0 \\
\hline Number of replications & 1,000 & & 1,000 & & 1,000 & & 1,000 & \\
\hline
\end{tabular}

Note: The groups are the same as in Table 2. The dependent variable is a dummy for whether the respondent is suffering or has suffered from wasting, stunting, underweight, and/or anthropometric failure. Standard errors are in parentheses. ${ }^{*} p<0.1, * * p<$ $0.05, * * * p<0.01$.

\subsubsection{Severe undernutrition in children under five with $a<-3$ standard deviation cut-off}

Following Chalasani (2012), we also examine severe forms of stunting and underweight (Table 5), showing that once again, household economic status (household wealth) is the most important contributor to improvement in severe childhood undernutrition at $65 \%$ and $69 \%$ for stunting and underweight, respectively. Maternal characteristics also remain relatively important, particularly for severe underweight, with a contribution of $39 \%$.

Table 5: Non-linear decomposition of socio-economic differences in severe undernutrition among Indian children under five: IHDS 2004/2005-2011/2012 (based on probit estimates)

\begin{tabular}{lcccc}
\hline & $\begin{array}{c}\text { Severe } \\
\text { wasting }\end{array}$ & Contribution & $\begin{array}{c}\text { Severe } \\
\text { stunting }\end{array}$ & $\begin{array}{c}\text { Contribution } \\
\text { Contribution } \\
\text { underweight }\end{array}$ \\
\hline $2004-2005$ & & $\%$ & & $\begin{array}{c}\text { Severe } \\
\%\end{array}$ \\
$2011-2012$ & 0.0625 & & 0.2539 & 0.1348 \\
Total difference & 0.0573 & & 0.1751 & 0.1022 \\
& -0.0052 & & -0.0788 & -0.0326
\end{tabular}

4 To check the possible biases from path dependence, and also to measure the case of severe undernutrition in under-five Indian children, we also randomize the variable order and re-run the estimates with 1,000 and 5,000 replications. The results, available from the authors upon request, are qualitatively similar. 


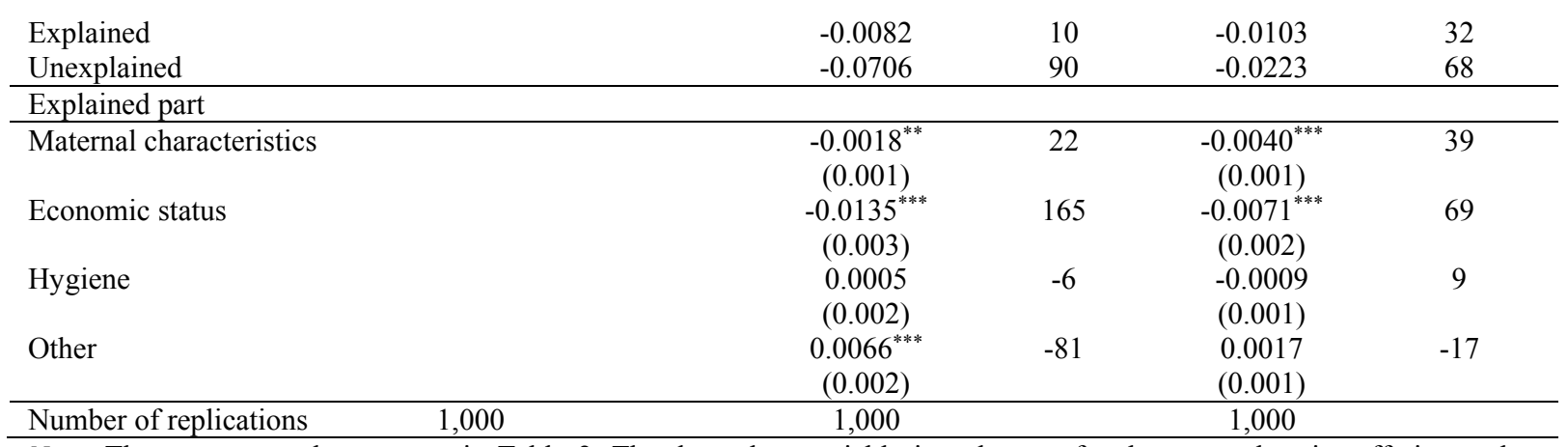

Note: The groups are the same as in Table 2. The dependent variable is a dummy for the respondent is suffering or has suffered from wasting, stunting, underweight, and/or anthropometric failure. Standard errors are in parentheses. $* p<0.1, * *$ $p<0.05, * * * p<0.01$.

Taken together, the results for the BO, non-linear, and IRFR decompositions suggest that household economic status (proxied by household wealth) consistently makes the largest contribution to the explained part of the observations, irrespective of whether the measure used is the WHZ, HAZ, or WAZ. The same holds for CIAF in the non-linear decomposition. Maternal characteristics are also important, however, especially for severe underweight, all three percentiles of the $W H Z$, and the $25 \%$ and $50 \%$ quantiles of WAZ. These outcomes conform closely to earlier decomposition results for India based on NFHS data (Chalasani, 2012; Mazumdar, 2010; Van de Poel \& Speybroeck, 2009), suggesting that the underlying drivers of child undernutrition in India have remained the same.

\section{Conclusions}

The poor nutritional outcomes for children in India, coupled with the high economic growth rates in recent decades, have been the subject of much research. Not only is India the largest contributor to the critical public health problem of wasting in South Asia (UNICEF, 2013), but it has the worst record for stunting in children under five. Nevertheless, the studies that yielded these observations are based on data that are over a decade old, so although their identification of the most adversely affected socio-economic groups is useful, the international community still has limited understanding of the critical factors contributing to undernutrition in Indian children.

To help remedy this problem, we analyse recently released data from phases I (2004/2005) and II (2011/2012) of the nationally representative Indian Human Development Studies to provide a more up-to-date and comprehensive profile of the key demographic and socio- 
economic determinants of undernutrition in Indian children under five. In a first analytic step, we use $z$-scores for weight-for-height (WHZ), height-for-age (HAZ), weight-for-age (WAZ), and overall anthropometric failure $(C I A F)$ to sketch undernutrition trends in this population from 2005 to 2012, which allows us to identify any changes in nutritional outcomes. Next, using conventional BO decomposition, we assess the disaggregated contributions of demographic and socio-economic determinants to the changes in various indicators of child undernutrition over the period under study. In this way, we are able to identify the characteristics that are most effective in explaining child nutrition so that they can be better targeted by policy intervention. We then introduce an unconditional quantile decomposition technique - the re-centred influential function regression (RIFR) - to identify the contributions of demographic and socio-economic characteristics at different quantiles of the unconditional marginal distribution of the childhood undernutrition distribution. Because our wasting, stunting, underweight, and anthropometric failure measures are all binary, we are able to overcome any possible biases from the conventional BO decomposition by applying the non-linear decomposition technique proposed by Fairlie (1999).

Our analysis yields the following major findings: First, even though more children were represented in the higher wealth quintiles in IHDS-II (2011-2012), wasting had worsened slightly since IHDS-I (2004-2005). Given that wasting results from a child being unable to take in adequate calories because of repeated infections and/or diarrhoea, a wasted child is at high risk of death. Nevertheless, a modest improvement is observable in stunting, underweight, and overall anthropometric failure, as well as in severe undernutrition. On the other hand, the CIAF scores reveal a much higher prevalence of child undernutrition, suggesting that conventional undernutrition indicators like wasting, stunting, and underweight may underestimate its actual extent. This finding is consistent with those of previous studies using older data sets (Nandy et al., 2005; Nandy \& Svedberg, 2012; Savanur \& Ghugre, 2015; Sen \& Mondal, 2012), underscoring the CIAF's validity for evaluating overall undernutrition and identifying children with multiple anthropometric failures.

In addition, even though our analysis points to uneven progress in improving $W H Z, W A Z$, and $H A Z$, all three decomposition techniques (BO, non-linear, and RIFR) indicate that household economic status consistently makes the largest contribution to the explained part of all three nutritional measures. It is also the largest contributor to the explained part of CIAF in the non-linear decomposition. Nevertheless, maternal characteristics also play a relatively 
important role, especially for severe underweight, all three percentiles of the $W H Z$ and $25 \%$ and $50 \%$ quantiles of WAZ. The robustness of these findings has important implications for the development of appropriate policies to address the critical factors that may be contributing to the slow progress in improving nutrition among India's children.

As highlighted by the recently released 2013 Lancet Maternal and Child Nutrition Series (MCNS) (Lancet, 2013), the new sustainable development agenda should prioritize all forms of undernutrition, with a special emphasis on nutrition-specific interventions and programs (e.g. addressing the immediate determinants of child undernutrition), nutrition sensitive programmes and approaches (e.g. addressing the underlying determinants of child undernutrition), and building an enabling environment (e.g. addressing the basic determinants of child undernutrition). Our research has highlighted the main determinants of undernutrition among Indian children. Appropriate policies focusing on these determinants (household wealth, maternal BMI and education) need to be fostered. It is worth noting that these lacklustre trends in child nutrition in India have occurred despite a funding increase from US\$35 million in 1990 to US\$170 million in 2000 for the ICDS program, and a 2005 Indian government decision to give high priority to its expansion. Moreover, although the ICDS is the most well-known of India's national dedicated maternal and child health nutrition and education programs, there are at least two other national and 10 regional nutrition and education programs, including the National Midday Meal Scheme, the National Rural Health Mission, the Comprehensive Rural Health Project, the Integrated Nutrition and Health Program, and the Public Distribution System. Unfortunately, these programs appear to compete rather than collaborate with one another in the achievement of optimal maternal and child health outcomes (Mann, Eble, Frost, Premkumar, \& Boone, 2010; Tarozzi, 2002).

\section{Acknowledgements}

This research uses data from the Indian Human Development Studies (IHDS) which was collected by the University of Maryland and the National Council of Applied Economic Research (NCAER), New Delhi. The usual disclaimer applies. 


\section{References}

Barker, D. J. (1995). Fetal origins of coronary heart disease. British Medical Journal, 311, 171-174.

Bhalotra, S., Valente, C., \& van Soest, A. (2010). The puzzle of Muslim advantage in child survival in India. Journal of Health Economics, 29, 191-204.

Blinder, A. S. (1973). Wage discrimination: Reduced form and structural estimates. Journal of Human Resources, 8, 436-455.

Brennan, L., McDonald, J., \& Shlomowitz, R. (2004). Infant feeding practices and chronic child malnutrition in the Indian states of Karnataka and Uttar Pradesh. Economics and Human Biology, 2, 139-158.

Cavatorta, E., Shankar, B., \& Flores-Martinez, A. (2015). Explaining cross-state disparities in child nutrition in rural India. World Development, 76, 216-237.

Chalasani, S. (2012). Understanding wealth-based inequalities in child health in India: A decomposition approach. Social Science and Medicine, 75, 2160-2169.

Deaton, A., \& Dréze., J. (2009). Food and nutrition in India: Facts and interpretations. Economic and Political Weekly, 44, 42-65.

Edoka, I. P. (2012). Decomposing differences in cotinine distribution between children and adolescents from different socio-economic backgrounds. University of York Health, Econometrics and Data Group Working Paper No. 12/29, York, UK.

Fairlie, R. W. (1999). The absence of the African American owned business: An analysis of the dynamics of self-employment. Journal of Labor Economics, 17, 80-108.

Fairlie, R. W. (2006). An extension of the Blinder-Oaxaca decomposition technique to logit and probit models. IZA Discussion Paper No.1917.

Fairlie, R. W. (2016). Addressing path dependence and incorporating sample weights in the non-linear Blinder-Oaxaca technique for logit, probit and other non-linear models. Race and the Digital Divide Discussion Paper, University of California, Santa Cruz.

Filmer, D., \& Pritchett, L. H. (2001). Estimating wealth effects without expenditure data - or tears: An application to educational enrollments in states of India. Demography, 38, 115-132.

Firpo, S., Fortin, N. M., \& Lemieux, T. (2009). Unconditional quantile regressions. Econometrica, 77, 953-973.

Gragnolati, M., Shekar, M., Das Gupta, M., Bredenkamp, C., \& Lee, Y. K. (2005). India's undernourished children: A call for reform and action. Health, Nutrition, and Population Discussion Paper, World Bank, Washington, DC.

Grantham-McGregor, S. (1995). A review of studies of the effect of severe malnutrition on mental development. Journal of Nutrition, 125, 2233S-2238S.

Haddad, L., Achadi, E., Bendech, M. A., Ahuja, A., Bhatia, K., Bhutta, Z., Blössner, M., Borghi, E., Colecraft, E., de Onis, M., Eriksen, K., Fanzo, J., Flores-Ayala, R., Fracassi, P., Kimani-Murage, E., Nago Koukoubou, E., Krasevec, J., Newby, H., Nugent, R., Oenema, S., Martin-Prével, Y., Randel, J., Requejo, J., Shyam, T., Udomkesmalee, E., \& Reddy, K. S. (2015). The Global Nutrition Report 2014: Actions and accountability to accelerate the world's progress on nutrition. Journal of Nutrition, 145, 663-671.

Hammer, J. S., \& Spears, D. (2013). Village sanitation and children's human capital: Evidence from a randomized experiment by the Maharashtra government. Policy Research Working Paper, World Bank, Washington, DC.

Jann, B. (2008). The Blinder-Oaxaca decomposition for linear regression models. Stata Journal, 8, 453-479.

Jones, F. L. (1983). On decomposing the wage gap: A critical comment on Blinder's method. Journal of Human Resources, 18, 126-130.

Kassouf, A. L., \& Senauer, B. (1996). Direct and indirect effects of parental education on malnutrition among children in Brazil: A full income approach. Economic Development and Cultural Change, $44,817-838$. 
Kumar, A., \& Kumari, D. (2014). Decomposing the rural-urban differentials in childhood malnutrition in India, 1992-2006. Asian Population Studies, 10, 144-162.

Kumar, A., \& Singh, A. (2013). Decomposing the gap in childhood undernutrition between poor and non-poor in urban India, 2005-06. PLoS ONE, 8, e64972.

Lokshin, M., Das Gupta, M., Gragnolati, M., \& Ivaschenko, O. (2005). Improving child nutrition? The integrated child development services in India. Development and Change, 36, 613-640.

Lancet (2013). Executive summary of the Lancet Maternal and Child Nutrition Series. The Lancet.

Machado, J. A. F., \& Mata, J. (2005). Counterfactual decomposition of changes in wage distributions using quantile regression. Journal of Applied Econometrics, 20, 445-465.

Maitra, P., Rammohan, A., Ray, R., \& Robitaille, M.-C. (2013). Food consumption patterns and malnourished Indian children: Is there a link? Food Policy, 38, 70-81.

Mann, V., Eble, A., Frost, C., Premkumar, R., \& Boone, P. (2010). Retrospective comparative evaluation of the lasting impact of a community-based primary health care programme on under-5 mortality in villages around Jamkhed, India. Bulletin of the World Health Organization, 88, $727-$ 736.

Mazumdar, S. (2010). Determinants of inequality in child malnutrition in India. Asian Population Studies, 6, 307-333.

Murray, C. J. L., \& Lopez, A. D. (1997). Global mortality, disability, and the contribution of risk factors: Global Burden of Disease Study. The Lancet, 349, 1436-1442.

Nandy, S., Irving, M., Gordon, D., Subramanian, S. V., \& Smith, G. D. (2005). Poverty, child undernutrition and morbidity: New evidence from India. Bulletin of the World Health Organization, 83, 210-216.

Nandy, S., \& Svedberg, P. (2012). The Composite Index of Anthropometric Failure (CIAF): An alternative indicator of malnutrition in young children. In V. Preedy (Ed.), Handbook of anthropometry: Physical measures of human form in health and disease. London: Springer.

Oaxaca, R. (1973). Male-female wage differentials in urban labor markets. International Economic Review, 14, 693-709.

Pathak, P. K., \& Singh, A. (2011). Trends in malnutrition among children in India: Growing inequalities across different economic groups. Social Science \& Medicine, 73, 576-585.

Paul, V. K., Sachdev, H. S., Mavalankar, D., Ramachandran, P., Sankar, M. J., Bhandari, N., Sreenivas, V., Sundararaman, T., Govil, D., Osrin, D., \& Kirkwood, B. (2011). Reproductive health, and child health and nutrition in India: Meeting the challenge. The Lancet, 377, 332-349.

Pelletier, D. L. (1994). The potentiating effects of malnutrition on child mortality: Epidemiologic evidence and policy implications. Nutrition Reviews, 52, 409-415.

Prüss-Üstün, A., Bos, R., Gore, F., \& Bartram, J. (2008). Safer water, better health: Costs, benefits and sustainability of interventions to protect and promote health. Geveva: World Health Organization.

Ray, R. (2007). Changes in food consumption and the implications for food security and undernourishment: India in the 1990s. Development and Change, 38, 321-343.

Ray, R., \& Lancaster, G. (2005). On setting the poverty line based on estimated nutrient prices: Condition of socially disadvantaged groups during the reform period. Economic and Political Weekly, 40, 46-56.

Savanur, M. S., \& Ghugre, P. S. (2015). Magnitude of undernutrition in children aged 2 to 4 years using CIAF and conventional indices in the slums of Mumbai city. Journal of Health, Population and Nutrition, 33, 1-7.

Schwiebert, J. (2015). A detailed decomposition for non-linear econometric models. Journal of Economic Inequality, 13, 53-67.

Sen, J., \& Mondal, N. (2012). Socio-economic and demographic factors affecting the Composite Index of Anthropometric Failure (CIAF). Annals of Human Biology, 39, 129-136.

Spears, D. (2012). Effects of rural sanitation on infant mortality and human capital: Evidence from India's Total Sanitation Campaign. Washington, DC: Princeton University.

Spears, D. (2013). How much international variation in child height can sanitation explain? Policy Research Working Paper, World Bank, Washington, DC. 
Srinivasan, C. S., Zanello, G., \& Shankar, B. (2013). Rural-urban disparities in child nutrition in Bangladesh and Nepal. BMC Public Health, 13, 1-15.

Strauss, J., \& Thomas, D. (1995). Household resources: Empirical modelling of household and family decisions. In: Srinivasan, T., Behrman, J. (Eds.), Handbook of development economics, vol 3A. Amsterdam: North Holland Press.

Subramanyam, M. A., Kawachi, I., Berkman, L. F., \& Subramanian, S. V. (2010). Socio-economic inequalities in childhood undernutrition in India: Analyzing trends between 1992 and 2005. PLoS ONE, 5, e11392.

Svedberg, P. (2000). Poverty and undernutrition: Theory, measurement and policy. New Delhi: Oxford India Paperbacks.

Smith, L.C., \& Haddad, L. (2015). Reducing child undernutrition: Past drivers and priorities for the Post-MDG Era. World Development, 68, 180-204.

Tarozzi, A. (2002). Estimating comparable poverty counts from incomparable surveys: Measuring poverty in India. Research Program in Development Studies Paper, Woodrow School of Public and International Affairs.

Tarozzi, A., \& Mahajan, A. (2007). Child nutrition in India in the nineties. Economic Development and Cultural Change, 55, 441-486.

Tomkins, A., \& Watson, F. (1989). Malnutrition and infection: A review. Nutrition Policy Discussion Paper No. 5, ACC/SCN, Geneva.

UNDP (United Nations Development Programme) (2007). 2007/2008 UNDP Human Development Report: Fighting climate change, human solidarity in a divided world. New York: UNDP.

Uthman, O. A. (2009). Decomposing socio-economic inequality in childhood malnutrition in Nigeria. Maternal and Child Nutrition, 5, 358-367.

UNICEF. (2013). Improving child nutrition: The achievable imperative for global progress. New York: United Nations Children's Fund.

Van de Poel, E., \& Speybroeck, N. (2009). Decomposing malnutrition inequalities between scheduled castes and tribes and the remaining Indian population. Ethnicity and Health, 14, 271-287.

Waterlow, J. C., Buzina, R., Keller, W., Lane, J. M., Nichaman, M. Z., \& Tanner, J. M. (1977). The presentation and use of height and weight data for comparing the nutritional status of groups of children under the age of 10 years. Bulletin of the World Health Organization, 55, 489-498.

WHO Multicentre Growth Reference Study Group. (2006). WHO child growth standards: Length/height-for-age, weight-for-age, weight-for-length, weight-for-height and body mass indexfor-age: Methods and development. Geneva: World Health Organization. 


\section{Appendix:}

Table A1 Anthropometric failure groups among children under five

\begin{tabular}{llccc}
\hline Group & Description & Wasting & Stunting & Underweight \\
\hline A & $\begin{array}{l}\text { No failure: Children whose height and weight are above the age-specific } \\
\text { norm and do not suffer from any anthropometric failure }\end{array}$ & No & No & No \\
B & $\begin{array}{l}\text { Wasting only: Children with acceptable weight and height for their age but } \\
\text { who have subnormal weight- for- height }\end{array}$ & Yes & No & No \\
C & $\begin{array}{l}\text { Wasting and underweight: Children with above norm heights but whose } \\
\text { weight-for- age and weight-for-height are too low. }\end{array}$ & Yes & No & Yes \\
D & $\begin{array}{l}\text { Wasting, stunting, and underweight: Children who suffer from } \\
\text { anthropometric failure on all three measures }\end{array}$ & Yes & Yes & Yes \\
E & $\begin{array}{l}\text { Stunting and underweight: Children with low weight-for-age and low } \\
\text { height-for-age, but who have acceptable weight for their height }\end{array}$ & No & Yes \\
F & $\begin{array}{l}\text { Stunting only: Children with low height-for-age but who have acceptable } \\
\text { weight, both for their age and for their short height. }\end{array}$ & No & Yes \\
Y & Underweight only: Children who are only underweight. & Yes & No
\end{tabular}

Source: Based on Nandy and Svedberg (2012).

Note: The theoretical combination of wasting and stunting is not physically possible because a child cannot simultaneously experience wasting and stunting and not be underweight. 